\title{
Whose knowledge, whose values? An empirical analysis of power in transdisciplinary sustainability research
}

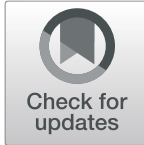

\author{
Livia Fritz ${ }^{*}$ (1) and Claudia R. Binder
}

\begin{abstract}
The participation of practitioners in transdisciplinary sustainability research has been heralded as a promising tool for producing 'robust' knowledge and engendering societal transformations. Although transdisciplinary approaches have been advanced as an effective avenue for generating knowledge positioned to question and transform an unsustainable status quo, the political and power dimensions inherent to such research have hardly been discussed. In this article, we scrutinise the constitution of participation in transdisciplinary research through a power lens. Guided by social theories of power and a relational understanding of participation, we analyse how diverse actors equipped with a variety of material and ideational sources wield power over the subjects, objects, and procedures of participation. We applied a qualitative meta-analysis of five transdisciplinary projects from a major German research funding programme in the field of sustainability to unveil the ways in which the funding body, researchers, and practitioners exercise instrumental, structural, and discursive power over (i) actor selection and (re-)positioning, (ii) agenda setting, and (iii) rule setting. We found that researchers primarily exert instrumental power over these three elements of participation, whereas practitioners as well as the funding body wield primarily structural and discursive power. By elucidating tacit and hidden power dynamics shaping participation in transdisciplinary research, this article provides a basis for improving process design and implementation as well as developing targeted funding instruments. The conclusions also provide insights into barriers of participatory agenda setting in research practice and governance.
\end{abstract}

Keywords: Participation, Power, Transdisciplinary research, Transformation, Discourses, Science policy and funding

\section{Introduction}

The United Nations' '2030 Agenda for Sustainable Development' is a prominent example of how a rethinking of our ways of researching and governing sustainability problems has become a priority on the international policy agenda [1]. In the face of complex and highly interconnected problems such as those embodied in the Sustainable Development Goals, calls for new, often participatory approaches to science and knowledge production have gained momentum [2]. Such proposals are generally rooted in the perspective that the monopoly of science over the production of trustworthy knowledge that should 'speak truth to power' is deficient in the face

\footnotetext{
*Correspondence: livia.fritz@epfl.ch

*Correspondence: livia.fritz@epfl.ch
École Polytechnique Fédérale de Lausanne (EPFL), Laboratory for

Human-Environment Relations in Urban Systems (HERUS), Station 2, 1015 Lausanne, Switzerland
}

of complex problems [3]. In response to these 'grand' societal challenges [4], science policy and research funding programmes under the umbrella of 'responsible research and innovation' increasingly ask researchers to co-create knowledge with policymakers, businesses, and civil society actors [5, 6], thus extending knowledge production to actors beyond the scientific realm.

In sustainability research, transdisciplinary (TD) approaches that incorporate practitioners and their expertise into the research process have emerged as promising tools for ensuring relevant research agendas, ${ }^{1}$ producing

\footnotetext{
${ }^{1} \mathrm{~A}$ broad range of terms has been used to designate those participating, including extra-scientific actors, stakeholders, practice actors, non-academic partners, and non-certified experts. For simplicity, we rely on the notion of 'practitioner' in a broad sense to designate any type of extra-scientific actor. Although these actors might have academic training, they do not conduct research as their main profession.
} 
'robust' knowledge and engendering societal change towards desirable futures [7-9]. Societal goals commonly associated with TD research relate to the empowerment of certain ideas as well as the participating practitioners ('power to') $[10,11]$ or to the stimulation of societal learning ('power with') [12]. In order to unleash this potential, design principles of TD research allude to ideals of 'co-leadership' and interactions between researchers and practitioners on 'equal footing' [11-13], thus assuming a 'symmetry of enlightenment' between researchers and practitioners and implying balanced power relations between the heterogeneous participants [14]. Such ideals also manifest in popular conceptualisations of participation in TD scholarship in terms of practitioners' degree of influence on the collaboration [15], thereby taking up the quest for power redistribution to the 'powerless' as represented in Arnstein's much-cited ladder of participation [16].

However, living up to these ideals in the practice of TD sustainability research can be challenging. Desired sustainable futures and their associated pathways are hotly contested $[17,18]$, and recognising participation as relational processes $[19,20]$ that are co-produced with the socio-political context [21] demands the disclosure of the negotiations, conflicts, and power dynamics that shape these processes. As Nowotny et al. put it with regard to the space between research and practice, called the 'agora': 'The agora, therefore, is not an empty or an anarchic place; [...] Of course, it would be naive to claim the agora is devoid of power structures and power struggles. Power certainly matters' ([22], p., 211).

In line with this view of the significance of power at the research-practice interface, scholars have increasingly stressed the need to recognise the entanglements of power and participation in TD research [10, 23-25]. Previous studies have examined how power relations among researchers [26], between researchers and practitioners, and among practitioners influence processes and outcomes of participation in research [10, 27, 28]. Against the backdrop of funding contexts and the wider academic system [29], the unequal distribution of financial and time resources has been found to engender power asymmetries between researchers and practitioners in TD projects [24, 30, 31]. Moreover, in the context of wider macro-societal power relations, the dominance of individual participants has been reported as another manifestation of power occurring in both single participatory events [32] and over the course of longer-term TD processes [33]. Building on and combining diverse knowledge sources has also highlighted the varying degrees of reliability, trustworthiness, and authority which they are assigned [24, 34, 35]. Such reflections on power asymmetries between diverse participants have impacted the very conceptualisation of TD, as how strongly different practitioners influence the problem definition, the choice of knowledge production approach(es), and related decisions have been advanced as definitive criteria in distinguishing 'participatory' vs. 'consulting' approaches [36].

Despite the growing recognition that 'power matters' and pervades TD processes [37], empirical explorations of its role are limited, and existing studies have rarely been grounded in explicitly articulated understandings of power [38]. Among the very few studies that have offered empirical insights into how power shapes researcher-practitioner interactions, most have relied on single case studies and the perceptions of researchers, thus neglecting the practitioners' experiences. In this article, we scrutinise the constitution of participation practices in TD research through a power lens in an effort to illuminate the often tacit and hidden power relations shaping them. Guided by social theories of power and a relational understanding of participation, we ask how and on what basis different actors wield power over the subjects, objects, and procedures of participation in TD research. By means of a qualitative meta-analysis of five TD projects from a major German funding programme in the field of sustainability research, we unveil the ways in which the funding body, researchers, and practitioners wield instrumental, structural, and discursive power over (i) the actors, their roles, and respective positioning; (ii) the setting of the research agenda and the definition of issues; and (iii) the setting of rules governing their interactions. Through an integrated consideration of the different actors' exercise of power, we elucidate power dynamics and moments of shifting power relations. In assessing the very practices of participation that lie at the core of various approaches to researching and governing sustainability problems, this article contributes to critical sustainability and future-orientated studies that are aware of power dynamics and critical of their own practices. A better understanding of the often-hidden workings of power in TD research can facilitate a conscious reflection on power dynamics and thus contribute to more reflexive process design and implementation as well as provide guidelines for targeted funding structures.

The remainder of this article is organised as follows: Section 2 lays the conceptual and theoretical foundations, introducing dimensions and sources of power and relating them to key elements of participation. Section 3 describes the methods and the empirical materials used in this research. Building on the proposed theoretical lens, Section 4 presents findings of how different actors exercise power over participation practices, and then, we critically discuss theoretical and practical implications for research practice and governance in Section 5.

\section{Theoretical framework}

Our theoretical framework rests on two pillars: (i) relational theories of power and (ii) conceptual elements of participation. 


\section{Conceptualising power}

Power is a contested concept that is filled with a profusion of meanings. In this article, we rely on relational theories of power and follow approaches that integrate both structures and actors in the analysis of power. Following Fuchs and Glaab [39] and Partzsch and Fuchs [40], we consider three dimensions of power, namely instrumental, structural, and discursive power. ${ }^{2}$ Adopting this multidimensional framework enables us to study both the exercise of power by actors and the power embodied in established institutions and norms [43]. The exercise of power rests on different sources of power or varying combinations of sources. When needed, we complement conceptions developed for political decision-making processes with literature concerning power in participatory development research and emphasise particularly pertinent aspects regarding participation in knowledge production processes [42].

\section{Dimensions and sources of power over}

Power over refers to power that is wielded over actors, structures, and discourses. Weber [44] established a widely used definition of power as the realisation of one's own will in asymmetrical relations. Power over is often distinguished along three dimensions [40]:

Instrumental power refers to the classic understanding proposed by Dahl [45], who emphasised the direct influence of an actor over another actor and described power as the ability of actor A to get actor B to do something that $B$ might not otherwise do. The capacity of actors to mobilise material sources in order to influence a decision or process is at the core of this dimension [46]. Instrumental power is visible in decision-making processes and formal rules [47], as well as in the influence of actors on formal political decision-makers, such as via lobbying [39].

Structural power builds on the work of Bachrach and Baratz [48] and focuses on the material and structural conditions influencing actors' decisions. In this broader notion of power, structural-material power predetermines processes of decision-making and non-decision making by shaping both the options and behaviour of actors. This concept focuses on the material and ideational structures that shape actors' decision options and allocate indirect and direct influence [40]. While from the perspective of instrumental power, the absence of certain actors from a process or debate appears to be due to these actors' own inaction, considering structural power allows us to understand the same observation as the result of a mechanism of exclusion and hence an exercise of power. For instance, structural

\footnotetext{
${ }^{2}$ We acknowledge that the multidimensional nature of power includes not only diverse facets of power over, but also power to and power with [41]. However, in this article, we focus exclusively on different facets of power over, partly based on [42], and do not address intersections with power with and power to. For further elaboration, please see [42].
}

power is exercised by restricting participation in decisionmaking to issues that align with the status quo [49]. This form of power is exercised through excluding or discrediting the concerns of others [47]. Structural power is also observed when the rules of the game allow some actors a smooth access to the process while hampering others' meaningful participation. In order to be heard, initially excluded actors who are granted access to a process may need to learn and adopt the language, behaviour, or knowledge of the powerful and incumbent actors in this process [46].

Discursive power is derived from Lukes' [50] 'radical view' of power that can also be exerted if actor B consciously wants to do what actor A desires. Discursive power is exercised through influencing the desires and beliefs of B [51]. This dimension refers to invisible and subtle forms of power [47], which rest primarily on ideational sources, such as values, norms, and ideas, when trying to influence an agenda or a process [39]. Knowledge and the control of it are key sources for the exercise of discursive power [46]. Relying on Foucault's [52] understanding of power, also the construction of subjectivity and individuality constitute an exercise of discursive power. Work on discursive power has highlighted that power not only pursues and serves interests but also generates them in the first place. This dimension stresses the role of accepted truths and knowledge about desirable developments, thereby uncovering the interrelations between discursive power, legitimacy, and authority [40].

As briefly indicated in the above descriptions, each of the three dimensions of instrumental, structural, and discursive power draws on the conditions and resources necessary to exercise power. While the literature on power offers a myriad of categorisations of these so-called sources of power, scholars mostly concur in broadly differentiating between material and ideational sources of power [43].

Material sources of power can be of actor-specific or structural nature and include the financial means that actors hold as well as their access to natural and technological assets such as communication infrastructures [43]. Material sources provide actors not only with direct decisionmaking power and agenda-setting power, but also the structural contexts that equip them with direct rule-setting or regulatory power. Agenda-setting power and rule-setting power overlap if agendas are about rules [39].

Ideational sources of power derive from social constructs such as ideas, values, and norms [43]. In the context of this study, sustainability and sustainable development figure as such constructs. Similarly, perceptions of actors as legitimate, knowledgeable, or trustworthy can provide ideational sources of power. Like material sources, ideational sources of power are relative. For instance, the power of an idea-e.g., stakeholder participation in science-exists only in relation to other ideas-e.g., objective 
science. Authority, legitimacy, and knowledge constitute crucial sources of ideational power allowing an actor's power to increase in relation to others. Importantly, these sources of ideational power are interrelated. For example, knowledge becomes more powerful when it is linked to legitimacy, and actors tend to be perceived as more legitimate when they invoke certain kinds of knowledge [39]. Authority can be described as the socially acknowledged right to make judgments, take decisions, or conduct actions [53], and it is formed by the relative status or position within the wider institutional context of the participating actors [54]. Legitimacy refers to an actor's ability to publicly represent a group of actors or speak on behalf of an issue. An actor can rely on legitimacy by invoking norms and values that are widely recognised or considered attractive. Hence, an actor with legitimacy draws their power from the status of the values they represent [54]. Likewise, the legitimacy of particular processes and measures is linked to their fit with dominant societal norms and may be enhanced through the framing of policy options or decisions in terms of such norms. The activation of attractive norms provides an important source of power to actors in pursuit of their interests [39]. Knowledge in the sense of the processing of information constitutes another ideational source of power [39]. Being attentive to the situatedness of knowledge [55] requires the acknowledgement that the different actors' status as credible and 'certified' experts affects what is considered trustworthy knowledge, fact, or even truth [56, 57].

\section{Conceptualising participation}

Our perspective on participation encompasses the involvement of practitioners and the inclusion of their expertise in TD research. For the development of a power lens on participation in TD, we build on conceptual elements that have been developed in participation studies, particularly in constructivist science and technology studies.

Following the 'ecologies of participation' approach [21], participation practices comprise three main elements: subjects (who), objects (what), and models of participation (how) (Fig. 1). 'Subjects' denotes the actors who take part in and enact a participation practice. 'Objects' refers to the issues at stake and the concerns that are debated and formed in the participation practice. 'Models of participation' refers to the procedural formats of the participation practice.

These three elements of participation-subjects (who), objects (what), and procedures (how)-are co-produced with the wider societal contexts as well as the knowledge and political cultures in which they are embedded $[21,58]$. Conceiving of them as co-produced allows us to be attentive to power in the making of participation in TD research. Norms, discourses, and structures in the respective academic and practice contexts in which a TD project is set can shape power relations within that project in important ways. At the same time, a project and some of the participating actors implicitly or explicitly aim at altering or maintaining the surrounding structures, discourses, and norms or do so in unintended ways [59] (Fig. 1).

We assume that each of the constituent elements (subject, object, procedures) of participation practices in TD research provides opportunities for the exercise of power. Regarding 'subjects', power is wielded to include or exclude actors in a process and to convey status and roles among participants. Regarding the 'objects', setting the scope of investigated issues provides opportunities to

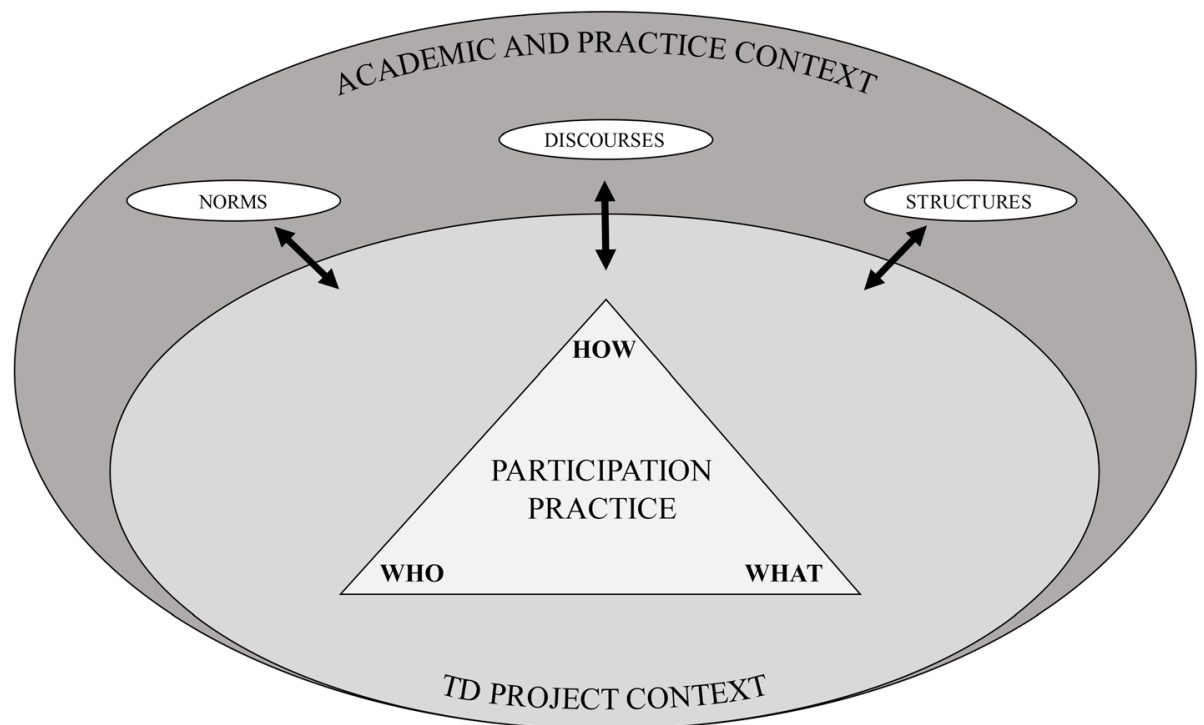

Fig. 1 Elements of participation in a TD project, embedded in context (adapted from [21]) 
Table 1 Forms of power in relation to elements of participation (authors' elaboration)

\begin{tabular}{|c|c|c|c|}
\hline $\begin{array}{l}\text { Element of participation/ } \\
\text { dimension of power }\end{array}$ & $\begin{array}{l}\text { Who (subjects) } \\
\text { Refers to the actors } \\
\text { interacting }\end{array}$ & $\begin{array}{l}\text { What (objects) } \\
\text { Refers to the agenda } \\
\text { of interactions }\end{array}$ & $\begin{array}{l}\text { How (procedures) } \\
\text { Refers to the rules } \\
\text { of interactions }\end{array}$ \\
\hline Instrumental & $\begin{array}{l}\text { Who decides who participates and } \\
\text { who directly influences this decision? }\end{array}$ & Who sets the agenda of the process? & $\begin{array}{l}\text { Who sets the rules of the } \\
\text { process and controls their } \\
\text { enactment? }\end{array}$ \\
\hline Structural & $\begin{array}{l}\text { In what ways do structural conditions } \\
\text { predetermine the selection and } \\
\text { participation of actors? }\end{array}$ & $\begin{array}{l}\text { In what ways do structural conditions } \\
\text { circumscribe the issues which enter } \\
\text { the agenda? }\end{array}$ & $\begin{array}{l}\text { In what ways do structural } \\
\text { conditions predetermine the } \\
\text { formats of participation? }\end{array}$ \\
\hline Discursive & $\begin{array}{l}\text { In reference to which norms and } \\
\text { ideas are actors selected and } \\
\text { positioned in the process? }\end{array}$ & $\begin{array}{l}\text { How do ideas and norms shape the } \\
\text { framing of issues and agendas? }\end{array}$ & $\begin{array}{l}\text { To what norms, ideas, or } \\
\text { standards do the formats } \\
\text { of participation allude? }\end{array}$ \\
\hline
\end{tabular}

wield power. Regarding the 'procedures' of how participation takes place, setting the rules of interaction and deciding on methods and locations constitute arenas for power exercise that determine who can meaningfully engage in the process. While analytically separate, knockon effects and path dependencies of power dynamics are conceivable across the elements constituting participation. For instance, the kind of power that different actors exercise regarding the 'procedures' might circumscribe some actors' options to shape the 'objects' of participation. Guided by this framework, we analyse how and on what basis different actors in TD projects exercise instrumental, structural, and discursive power over each of these elements of participation (Table 1). In the analysis, we distinguish three types of actors potentially exercising power-researchers, practitioners, and the funding body-and enquire into shifts in power relations between these actors in the constitution of participation.

\section{Materials and methods}

\section{Programme context and project selection}

This article is based on a meta-analysis of five on-going sustainability research projects that are part of a German research funding programme. The programme aims to foster societally relevant research that contributes to sustainable development. In order be eligible for funding, research projects must be interdisciplinary and include societal actors in the research process. Thus, the programme provides an empirical site for studying TD and participatory practices in the field of sustainability research. The funding programme was scientifically accompanied by a research project of which this study was part and which was conducted by an interdisciplinary group of researchers. The selection of projects for this study was based on the criterion of maximum diversity in terms of (i) institutions and disciplines, (ii) topics, and (iii) types of practitioners involved. Consequently, the analysed projects encompass a variety of sustainability issues and include researchers from diverse disciplines as well as practitioners with multifaceted professional backgrounds. The projects are part of two funding rounds (Table 2).

\section{Data collection}

We combined two types of materials. Firstly, we collected documents, including research proposals as well as programme documents such as the funding call and information material on the websites of the funding body. We conceive of such documents not as mere information containers that provide factual content on the (anticipated) research endeavour, but rather 'methodologically created communicative features' that require a consideration of the purpose (e.g., attracting funding), and the audiences for which they were produced (e.g., scientific reviewers) [60]. Secondly, we conducted 23 semi-structured interviews at different moments throughout the projects, consisting of 14 interviews with researchers and nine interviews with practitioners involved in the projects (Table 3). Relying on a purposeful sampling approach [61], we addressed principal investigators (PIs) as gatekeepers and asked them to establish contact with those researchers who were closely involved in research-practice interactions as well as practitioners who were participating in the projects. As data collection proceeded, a snowball technique [61] was used to enlist further interviewees.

The situatedness of this study in a research project that accompanied the funding programme had implications for the data collection process and our positioning in the field [55]. It entailed "fluid, every-changing positionalities" ([62], p., 747) in our relationship to the selected research projects and the actors within them, as well as to the funding body. Our position as 'official' accompanying researchers presumably gave legitimacy to the study and enhanced the researchers' motivation or even perceived obligation to participate in it. At the same time, being perceived in a role that was close to 
Table 2 Main characteristics of the selected TD projects according to project proposals

\begin{tabular}{|c|c|c|c|c|c|}
\hline Characteristics/project & A & B & C & $\mathrm{D}$ & $E$ \\
\hline Funding cohort & 2015 & 2015 & 2014 & 2014 & 2014 \\
\hline Planned project duration & 4 years & 4 years & 4 years & 3 years & 3 years and 3 months \\
\hline Thematic cluster & Health and education & $\begin{array}{l}\text { Regional } \\
\text { development }\end{array}$ & $\begin{array}{l}\text { Regional } \\
\text { development }\end{array}$ & Urban development & Technology \\
\hline $\begin{array}{l}\text { Range of submitted project } \\
\text { budget (EUR) }\end{array}$ & 1-1.5 million & 2.5-3 million & 2.5-3 million & $<500,000$ & 1.5-2 million \\
\hline $\begin{array}{l}\text { Number of academic institutes } \\
\text { listed as applicants }\end{array}$ & 4 & 8 & 7 & 3 & 7 \\
\hline Main type of practitioners involved & $\begin{array}{l}\text { Public service providers, } \\
\text { associations }\end{array}$ & $\begin{array}{l}\text { Public sector } \\
\text { actors }\end{array}$ & $\begin{array}{l}\text { NGOs, } \\
\text { associations }\end{array}$ & $\begin{array}{l}\text { NGOs, associations, public } \\
\text { sector actors, citizens }\end{array}$ & $\begin{array}{l}\text { Private sector actors, public } \\
\text { sector actors, 'consumers' }\end{array}$ \\
\hline $\begin{array}{l}\text { Letter of intent (LOI) of (selected) } \\
\text { practitioners }\end{array}$ & Yes & Yes & No & Yes & No \\
\hline $\begin{array}{l}\text { Reference to notion of } \\
\text { transdisciplinarity }\end{array}$ & $\begin{array}{l}\text { Strong (but mostly in the } \\
\text { interdisciplinary sense) }\end{array}$ & Strong & Strong & Strong & Weak \\
\hline $\begin{array}{l}\text { Financial resources for practitioners } \\
\text { according to budget plan }\end{array}$ & No & No & No & No & No \\
\hline
\end{tabular}

the funding body came with certain challenges, such as the fear of being evaluated and concomitantly a reluctance to granting an inside view into on-going knowledge production processes $^{3}$. Since how interlocutors perceive the interviewer is a key issue when conducting interviews [64], we paid due attention to explaining in detail the interest of the study (to better understand factors shaping TD research and participation processes therein) and to establish a trust relationship. Relations with the different interviewees varied according to their status (e.g. professors or PhD researchers) and gave rise to different power relations in interview situations [65]. The situatedness of this study within an accompanying research project introduced further actor dynamics to the research process. On the one hand, the relation between an accompanying research and the project 'under investigation' necessarily implies a relation of information asymmetries (i.e., we get to know their practices significantly better than they do ours). In order not to jeopardise the necessary trust relationship, anonymity, and confidentiality of any information obtained about the projects, its actors and processes were core principles of the accompanying research [66]. Throughout the research process, we affirmed interviewees that we were not evaluating projects and by no means reporting back to the funding body. On the other hand, the accompanying research heavily depended on the participation of the projects. In some situations, the interviewees clearly drew the boundaries of our access to their partners in

\footnotetext{
${ }^{3}$ The reluctance to share experiences with knowledge production processes might more generally reflect the uneasiness of granting an inside view on the messy processes involved in conducting (TD) research in a research culture that focuses on communicating the finished product rather than its making [63].
}

the practice field, thus assuming a powerful position relative to our research.

The interviews were semi-structured and problemcentred [67]. An interview guidance was used and adapted case-by-case. The guidance consisted of narrative questions about the initiation of the collaboration and the framing of the problem, the structures and forms of interactions between researchers and practitioners (including questions on decision-making processes, the division of roles, the kind of expertise exchanged), and the factors and boundary conditions shaping these interactions (including questions on resources). Additionally, actor influence mapping supported the interview questions about actors and their relations in the participation process [68]. On their basis, interviewees were asked to weigh the importance of the respective actors for achieving the overall project goal using a scale of 'very important', 'important' and 'less important'. They were

Table 3 Overview of interviews conducted with researchers and practitioners

\begin{tabular}{|c|c|c|}
\hline Project & $\begin{array}{l}\text { Interviewees } \\
\text { Research }\end{array}$ & $\begin{array}{l}\text { Interviewees } \\
\text { Practice }\end{array}$ \\
\hline A & $\begin{array}{l}1 \mathrm{PI} \\
2 \mathrm{PhDs} \\
1 \text { collaborator }\end{array}$ & $\begin{array}{l}1 \text { employee of public } \\
\text { service provider }\end{array}$ \\
\hline B & $\begin{array}{l}1 \text { PI } \\
1 \text { Postdoc } \\
1 \text { PhD }\end{array}$ & $\begin{array}{l}1 \text { political representative } \\
2 \text { public administration }\end{array}$ \\
\hline C & $\begin{array}{l}1 \text { PI, } \\
1 \text { Postdoc }\end{array}$ & $1 \mathrm{NGO} /$ association \\
\hline D & $\begin{array}{l}1 \mathrm{PI}(2 \times) \\
1 \text { collaborator }\end{array}$ & 2 NGOs/associations \\
\hline$E$ & $\begin{array}{l}1 \mathrm{PI} \\
1 \text { collaborator }\end{array}$ & $\begin{array}{l}1 \text { entrepreneur (SME) } \\
1 \text { company employee }\end{array}$ \\
\hline
\end{tabular}


furthermore invited to label the forms of interaction as either 'information', 'consultation', or 'cooperation'-a scale commonly used to assess intensities of involvement (e.g., [69]). Applying actor mapping proved effective for breaking the ice and guiding interviewees' attention to something tangible: the actors with whom they interacted. This facilitated interaction and allowed us to refer to these visual elements throughout the interview.

The interviews were conducted in January 2016, June 2017, December 2017, and Mai-June 2018. Thus, while all projects were still on-going, they were in different project phases at the time of data collection (see Table 1 for project duration). All interviews were recorded and transcribed verbatim. With one exception, the transcripts as well as most of the documents are in German. We translated the quotes provided in this article into English.

\section{Data analysis}

All materials were managed, coded, and analysed with the qualitative data analysis software 'MAXQDA'. We applied a structuring qualitative content analysis [70]. Building on the theoretical framework elucidated in the previous section ("Theoretical Framework"), the interview material was deductively analysed to derive codes from power theories (dimensions and sources) and pre-existing conceptual elements of participation (subject, objects, procedures). ${ }^{4}$ After the initial development of a theory-based system and definition of each code, we pre-tested its practicability with a sub-set of the material and discussed necessary refinements among the authors before proceeding with coding and analysing the entire material [70]. Although structuring qualitative content analysis is a 'concept-driven' coding procedure [71], this approach allowed us to inductively refine the code system during the testing phase. Acknowledging pre-existing concepts while allowing for their adaptation to our study context was particularly apt for operationalising abstract power theories in knowledge production contexts. The aggregation of findings was done such that it enabled mapping the diversity of ways in which power is exercised and shifting between actors in participation practices in TD research while ensuring the anonymity of interviewees and projects.

We relied on a reduced coding system for the analysis of both programme documents and research proposals. Similarly to Felt et al. [34], we followed Akrich's [72] approach to studying technologies and analysed the 'script' embedded in the funding programme, which constituted the immediate structures of action in which the actors engaged. We analysed programme documents regarding the ways in which they prescribed the subjects, objects, and procedures of

\footnotetext{
${ }^{4}$ Due to the on-going nature of the projects analysed, exercises of power regarding the outputs of participation were not considered in the analysis.
}

participation in the projects. The qualitative analysis of project proposals strove to capture imaginations and conceptions of participation and take into account the discursive formations that provide a frame for the narrations of the actors involved [73]. The analysis was focused on the underlying understanding of $\mathrm{TD}$, the actors involved, the procedures of participation planned, and their reflection in project structures and budgets. This approach supported the selection of projects for in-depth examination. Methods triangulation and data triangulation of sources were applied by combing different data collection methods and examining different data sources through similar methods [74].

\section{Results}

In this section, we present the ways in which the funding body, researchers, and practitioners wield power over the subject, objects, and procedures of participation in the five TD sustainability research projects analysed. For each element of participation analysed below, we differentiate the three actors' exercise of instrumental, structural, and discursive power, identify the sources on which they rely, and highlight shifts in power relations between them.

\section{WHO: power in actor selection and (re-)positioning}

The analysis of the subjects of participation unveils that power is exercised in the selection and assembling of actors as much as in the definition of the roles they assume and their respective positioning. Interviewees' narrations demonstrate that there is no one single power configuration in the sense of researchers over practitioners or vice versa.

\section{Funding body}

The funding body sets the requirement of involving practitioners into the research projects; however, it does not set any guidelines concerning whom to involve and ascribes the authority to do so to the applying researchers. While the funding body does not prescribe which types of actors should be included, it discursively frames potential participants as 'citizens' and 'concerned societal groups' (funding call 2014, 15) and invokes broad concepts such as 'civil society' (webpage of funding body) - as opposed to constructing actors as 'stakeholders' or 'experts' for instance. According to programme regulations, only scientific actors, i.e., professors, are entitled to submit project proposals and assume project leadership. Co-leadership with practitioners is not an explicit consideration (funding call 2014, 15). Based on its material sources, the funding body thus appears as a distant actor setting the cornerstones for the initial distribution of power over the selection of actors and in so doing wields structural power.

\section{Researchers}

Given the above-described structural conditions, the researchers wield instrumental power and decide whom to 
include in and exclude from their projects. Their power to do so rests on their status as the legitimate decisionmakers of the project as embedded in material and ideational sources and is reinforced by their authority over project structures and budget allocations. Consequently, the five analysed projects were each characterised by an initial definitorial moment in which power lies with one actor group. This general tendency was narrated by researchers (AR1, AR2, AR3, ER1, BR1) and practitioners (CP1, EP1, EP2) alike, as exemplified in the below excerpt of one practitioner's description of their happiness about being chosen by the researchers. The depiction clarifies that the decision on with whom to work was taken by the researchers:

They [the researchers] had visited several organisations and said they would take a decision after talking to everyone. And yes, then the verdict has fallen on us, and we are glad about it [laughs] (CP1).

Thus, in these initial configurations, researchers exert power over practitioners, whom they position according to their needs. In the absence of detailed LOIs defining the roles of different actors (research proposals A-E), the researchers devise the initial conception and distribution of roles, including the TD interactions. Across the projects, researchers wielded discursive power in ascribing the practitioners a myriad of roles and characteristics; they appeared as those who are most legitimate and able to identify relevant problems (BR1, BR2, CR2, ER2), as gatekeepers and mediators between different fields and actors (AR2, BR2, CR2, ER1, ER2), as multipliers and disseminators who spread research findings within their networks (AR3, AR3, AR4), and as an extended arm of the projects who will implement the research outputs (AR2, AR4, BR2, BR3).

Despite the researchers' instrumental decision power, in some cases - particularly when researchers were not established in their respective practice contexts - the selection of actors was perceived less as picking and choosing, but rather as a cumbersome and time-consuming exercise of convincing practitioners of the added value of participating (AR2, BR2, BR3, ER1, ER2). In contrast, narrations by researchers with established networks show that their entrenched status gave them credit, increased their trustworthiness, and endorsed them as partners among potential participants (AR2, AR3, AR4, BR3, CR2, ER2).

Both researchers (DR1b, DR2) and practitioners (BP1, DP2, EP1) depicted the process of extending and accepting invitations to participate as a negotiation process involving struggles over ideas and agendas. In a few such negotiations, researchers claimed that some practitioners conditioned their participation on high returns (DR1b, DR2) or 'acted in opportunistic ways' (DR2). Such attempts at negotiating collaboration terms and influencing agenda and rule-setting pushed the researchers to select other practitioners, thereby wielding instrumental power over actor selection on the basis of their authority as project leaders (DR1b).

\section{Practitioners}

Although researchers of the analysed projects were in charge of selecting practitioners and initiating the collaboration, starting and maintaining a collaboration is not a unilateral decision. Practitioners influenced the selection by clearly demonstrating their interest in participating or, conversely, articulating their scepticism concerning the project (BR3, DR2, ER2). Therefore, researchers do not wield total power over actor selection; practitioners decide to accept or decline invitations to participate, thereby wielding instrumental power over the future direction of the TD project (BR3, ER2).

Reflecting on their decisions to engage in their respective projects, practitioners who were part of larger companies or institutions particularly stressed that they could not have engaged in the project without support from important actors in their networks such as a superior in the company, the mayor in the municipality, or the director of the institution (AP1, BP2, BP3, EP2). Even when they are external to the project, such actors shape the setting up of collaborations and are influential in sustaining them. As their support means being authorised to participate, ${ }^{5}$ they exercise structural power over the subjects of participation. If such authorisation is not given or is revoked, then collaborations are ended or invitations for future collaborations are declined (BR3). This condition speaks of a more general observation of the individual participant's embeddedness in wider power relations, which are more or less conducive to their participation in the research projects.

Although researchers predefined practitioners' roles and positions in the project, the interviewees uncovered configurations in which the researchers were positioned by the practitioners and expected to assume certain roles. In practitioners' narrations, researchers were discursively constructed as idea-givers and advisors (BP2, $\mathrm{BP} 3, \mathrm{CP} 1, \mathrm{DP} 2)$, facilitators, organisers and project responsible actors (BP1, BP2, BP3, EP1, EP2), distant observers, or unpleasant evaluators (AR2, AR4). The exercise of power in the ascription of roles and

\footnotetext{
${ }^{5}$ For both practitioners and researchers (AR2, AR4, CR2), the support of powerful actors in their reference field such as professors and PIs appears as a source of power: One interviewee who was positioned at the interface to practitioners explained that more PI support in the beginning would have facilitated the TD process. This suggests that PIs have power based on their status as professors; such support would have given more weight to the collaboration with practitioners and motivated practitioners to engage more deeply (CR2).
} 
characteristics is particularly accentuated when researchers try to immerse in the field, i.e., interactions do not take place in spaces provided by the researchers such as workshops (AR2, AR3, AR4, DR2, DP1, DP2). One researcher in an urban development project described how she experienced being passively positioned by practitioners and reflected on ascriptions which she perceived as unjustified. Recalling her participation in practitioners' meetings, she described being perceived as arrogant and giving unsolicited advice. She was attributed authority based on preconceived images of 'researchers' or 'scientists', which hampered interactions among 'equals'. Stereotypes and assumptions about how the 'others' supposedly are and behave are discursively reproduced in the construction of actors. In her interpretation, her lack of knowledge of the cultural codes and behavioural norms in the practice context prevented her from being recognised as a legitimate actor, and the practitioners exercised power by delimiting her role in their association's meetings. Linked to this configuration of ideational sources, the practitioners exercised power by shaping the structural conditions of her entering the field.

The same researcher shared her struggles to define her own role amidst the contrasting expectations of the participating public and third sector actors. While some voiced their discontent about being advised, others explicitly expected to receive advice:

On the other hand, other people wanted us, so to speak, to assist them and advise them on any actions [...] Anyway, it was incredibly challenging to define your own role so that not too much expectation but also no rejection develops (DR2).

The PI of this project perceived that practitioners expected them to provide advice based both on their theoretical knowledge and relationships to important actors in the field. The PI interpreted the status of another researcher in the same project, who became a quasimember of another participating association and was allowed to document their activities, as recognition of his collaborator's legitimacy (DR1b). Hence, whereas the latter researcher succeeded in building ideational sources, the abovementioned researcher (DR2) was not accepted as a legitimate participant in practitioners' meetings. In both cases, the practitioners decided who was allowed to enter their every-day practices and used mechanisms of inclusion and exclusion and positioning actors at the centre or the periphery. Such exercises of structural power are rooted on their position in the practice context and their knowledge of behavioural norms.

Such diverse ascriptions reflect the ways in which the actors position themselves vis-à-vis their main reference field, i.e., the academic or the practice context. Power particularly surfaces when practitioners reposition themselves in reaction to conflicts or overstressed capacities (AR2, BR3, DP2, DR2). Power shifts occur as practitioners assert themselves by positioning themselves at greater distance to the researchers, thereby invoking norms in the practice context. They defend their interests and resist the roles that are being ascribed to them within the projects. The following extract from a practitioner working in the third sector reveals how mastering the communication and behavioural norms in the practice context constitute ideational sources of power and how its lack can create conflict:

There was this thing and someone was not happy recently and instead of calling this person-which is what we would do-she [the researcher] sent a very long email, which came across as offensive. And I told her, 'listen this is how you ruin relationships'. Since I was copied on her message, I received a call from [name of person] complaining what was going on. So, if the relationships here are lastingly spoiled, this is a problem. And I told her. Because this a cultural difference-while the researchers leave after the project, our work depends on sustainable networks (DP2).

Thus, not only the moment of initial selection of the subjects of participation, but also the sustained collaboration and commitment emerged in the interviews as decisive in the exercise of power. Particularly, practitioners' withdrawal or silent or outspoken threats of withdrawal constitute critical moments in shifting power relations through practitioners' manifestation of instrumental and structural power. According to the researchers' narrations, practitioners end their participation for manifold reasons. Some observed evidence of 'participation fatigue', which resulted in practitioners' decisions to refuse or end their participation despite repeated efforts from the researchers (BR3). Another researcher shared her disappointment in a practitioner's last-minute cancellation of a commonly developed teaching project due to a lack of financial and time resources, which strongly influenced the TD process and led to the collapse of the entire subproject. Researchers reported further experiences with the withdrawal of practitioners due to conflicts within their practice institutions (BR3), staff turnover, or a lack of trust in the relevance and usefulness of outputs (BR2, BR3). The latter reveals how practitioners exercise power by ending their participation or threating to do so if their concerns are not prioritised on the agenda or adequately addressed. In some practitioners' narrations, exercising power by withdrawing derived from a lack of sufficient financial support through the project and hence being neither responsible nor accountable for either the project's success or the quality of its outputs (BP1, DP2) (Table 4). 
Table 4 WHO: forms of power exercised by funding body, researchers, and practitioners

\begin{tabular}{|c|c|c|c|}
\hline $\begin{array}{l}\text { WHO: power in } \\
\text { actor selection }\end{array}$ & Funding body & Researchers & Practitioners \\
\hline Instrumental & - & $\begin{array}{l}\text { Deciding whom to involve or selecting } \\
\text { practitioners; based on their authority } \\
\text { as project leaders }\end{array}$ & $\begin{array}{l}\text { Deciding to decline an invitation to } \\
\text { participate, deciding to withdraw or } \\
\text { re-position; based on a lack of } \\
\text { accountability as non-formalised partners }\end{array}$ \\
\hline Structural & $\begin{array}{l}\text { Endorsing only researchers as applicants/PIs, } \\
\text { transferring project authority to them, thus } \\
\text { shaping the options of researchers and } \\
\text { practitioners; based on material-structural } \\
\text { sources }\end{array}$ & - & $\begin{array}{l}\text { Shaping the structural conditions of } \\
\text { researchers' entering the field } \\
\text { (behavioural and communication } \\
\text { norms), (de-)legitimising researchers } \\
\text { as actors in the field; based on } \\
\text { practitioners' legitimacy in the practice } \\
\text { context; silent or outspoken threat of } \\
\text { withdrawal, distant actors in the wider } \\
\text { practice context, authorising individual } \\
\text { actors to participate }\end{array}$ \\
\hline Discursive & $\begin{array}{l}\text { Framing practitioners in terms of 'citizens' } \\
\text { and 'concerned societal groups' as opposed } \\
\text { to 'experts', 'stakeholders' }\end{array}$ & $\begin{array}{l}\text { Ascribing roles to and positioning } \\
\text { the practitioners, constructing them } \\
\text { as 'legitimate problem identifiers', } \\
\text { 'implementers' or 'multipliers' }\end{array}$ & $\begin{array}{l}\text { Ascribing roles to and positioning the } \\
\text { researchers, constructing researchers as } \\
\text { 'advisors', 'evaluators' or 'organisers', } \\
\text { based on ideas of how the 'others' are }\end{array}$ \\
\hline
\end{tabular}

\section{WHAT: power in agenda setting}

Regarding the objects of participation, the funding body, researchers, and practitioners are found to exercise power in setting and shaping the agenda at different moments throughout the TD projects, in developing the research project and drafting the proposal, in defining and concretising research activities, and in setting the topics of meetings and workshops.

\section{Funding body}

The drafting of the research proposals that are submitted to the funding body constitutes critical moments of agenda setting. The funding body explicitly stresses its openness to any topic pertaining to sustainable development and does not predetermine the scope of possible issues to be included on the research agenda. Nonetheless, by calling for projects that promised to be not only societally relevant and contribute to sustainable development, but also scientifically excellent and original, ${ }^{6}$ the funding body exercises structural power by means of its material sources and discursively frames the nature of research agendas worthy of funding (funding call 2014, 15).

\section{Researchers}

Prior to project approval, researchers' dominance in setting the agenda is observed across projects. Interviewees' narrations about the genesis of the research projects reveal that instrumental power lay with the researchers,

\footnotetext{
${ }^{6}$ Researchers' reflections on the challenges they encounter in engaging in TD work suggest that these two requirements do not always converge (BR2, BR3) and are in their experience easier to combine for some disciplines (e.g., architecture) than for others (e.g., political science).
}

who initially set the overall research agenda and chose the approach to implement it. Only at a later stage did they invite practitioners to contribute. In several narrations, this agenda-setting procedure was portrayed as an inevitable result of the funding application process. As mentioned above, the funding body wields structural power and exclusively authorises researchers to apply for funding, thereby putting them in the key position during the proposal development phase. Furthermore, the researchers hold the financial resources to do so, which in the absence of seed money for project development (AR1) marks a critical source of power. Hence, researchers' power over the initiation of the projects and the agenda setting is based on their status as researchers, which authorises them to draft and submit the project proposals.

The practitioners often struggled to delineate the research project from other activities in the field and did not generally consider researchers' dominance in initial agenda setting to be problematic (BP1, BP2, BP3, DP1, DP3, EP1, EP2). Only one practitioner explicitly established a link between being involved in agenda setting and commitment to and influence on the process as well as greater use of its outputs (CP1). Quite on the contrary, others claimed that due to limited time and financial resources, they would not want to be involved prior to the official project approval by the funding body. They lacked the material-structural sources to influence this early stage of agenda setting (AP1, EP1, DP2) or discursively reproduce ideas of what they considered a beneficial division of labour between research and practice (DP2). How the lack of material sources and the mobilisation of ideational sources can overlap is 
reflected in comments by a practitioner who worked in the third sector:

There will be many, many preliminary talks and meetings about something, which I cannot, well, I really cannot afford to have preliminary talks, [...] because that is research-a lot of time is taken into account without any output. I don't have that time (DP2).

I think it is great that researchers want to engage, but it is also dangerous because it politicises research. There is a great division of labour if research stays true to its neutral character in pursuit of knowledge. [...] Because otherwise research risks being guided or dictated by political interests and becomes dogmatic. This we would vehemently criticize if actors from the other end of the political spectrum would do, but if it fits our political colour, it is fine? I am not sure (DP2).

\section{Practitioners}

At the proposal stage, the degree of practitioners' influence on initial agenda setting diverged across projects. Interviewees participating in one project explained that problems and needs of practitioners were gathered during meetings and workshops in a preparatory phase and considered by the researchers drafting the proposal (BR1, BR2, BR3). Others recalled that the research agenda was developed based on scientific interests (AR2, AR4) before being discussed with the involved practitioners (AR1). Interviewees from two projects indicated that prior contact with practitioners or building on previous projects with the same practitioners enabled their interests to indirectly enter the research agenda. In such cases, the research agenda was developed against the backdrop of lessons learned from these previous collaborations (BR2, BR3, CR2). Across these configurations, the indirect influence and discursive power exercised by practitioners was rooted in the idea that research should be societally relevant and/or applicable.

Several narrations suggest that the initial research agenda is adjusted after the project begins. In this process, practitioners' interests and dynamics in the practice context are considered (BR2, DR1b) and shifts in power relations occur. According to one researcher, the agenda inevitably has to be adapted to the reality in the field:

I am very critical concerning standard science - you put into an application what you will be doing in three years, and then once in the field, naturally you find out one or two things and knock things over because the field does not do what you had written in your application. Weird, eh, that reality does not adapt to your application [laughs] (DR1b).
To varying degrees, the concretisation of the research agendas or selected working packages took place jointly with the practitioners. Smaller sub-projects as well as student projects (BR2, BR1, BP1, BP2, BP3, DR1b, DR2, DP1, DP2, ER2, EP1, EP2) and teaching projects (DR2, DP1) were defined in collaboration with practitioners. In some cases, practitioners approached the researchers with consultation requests based on their needs (BR2). In these few cases, the practitioners wielded instrumental agenda-setting power, relying on their status and knowledge of matters of concern in the practice context. Across these configurations, the practitioners relied on ideational sources and activated the oft-mentioned desire of researchers of 'giving something back' (AR3, BR2, $\mathrm{BR} 3, \mathrm{DR} 2, \mathrm{ER} 1)$ to the practitioners and of keeping 'giving and taking in balance' (BP3, CP1, EP2).

Researchers from across the projects expressed the ideal of researching what really matters and what can be used by practitioners (AR2, AR2, AR3, AR4, BR1, BR2, BR3, DR1b, DR2, ER1, ER2) as opposed to 'ivory tower' research (AR3, BR3, CR2, DR2, ER1, ER2). In this context, those researchers spoke of a dependency on the practitioners, who wield discursive power over the formation of the research object-mobilising the ideal of conducting relevant and useful research to contribute to sustainability. Practitioners assume a powerful role in filtering which problems according to their values and interests are considered germane on the one hand, and which are realistically manageable on the other. As has been mentioned regarding actor positioning, researchers construct practitioners as the legitimatised to judge the relevance of the topic (BR1, BR2, CR2, ER2) as well as sufficiently knowledgeable to estimate the chances of uptake (AR2, AR4, BR2, BR3).

Asked about the setting of the agenda, practitioners also addressed the researchers' dependence on their inputs (BP1, BP2, EP2). As one policymaker participating in a regional development project explained:

Well, science depends on our bringing in problem areas, which we face. If we don't do that, they cannot do anything in these areas. So that's why I always had the feeling when I was there and participated that I was taken seriously and that I also had the opportunity to present our interest. That then it will also be taken into consideration (BP1).

The practitioner perceived themselves to exercise power over the research agenda due to their position in the practice context, which provided them with context knowledge and legitimised them to contribute to the identification of significant issues. Later in the interview, it became clear that mutual dependencies exist, while the researchers are dependent on practitioners for 
problem identification and ensuring that what is relevant enters the research agenda, policymaking needs research in order to be able to 'actively shape the future' (BP1).

Several narrations indicate that practitioners see themselves not only as those most knowledgeable about the relevant problems, but also as the participants who are able and legitimised to assess the chances of implementing solutions and judge their practicability (AP1, BP1, $\mathrm{BP} 2, \mathrm{BP} 3, \mathrm{CP} 1, \mathrm{EP} 1, \mathrm{EP} 2)$. This role perception is reflected in one policymaker's narration:

You were allowed to freely develop your ideas in the room and people from practice like us, you sometimes have to suppress a chuckle when one or two things are presented, because you know exactly that the idea behind it is great, but has zero prospect of implementation for whatever reasons (BP3).

In this filtering process, some issues are organised in and others are discursively closed down. Depending on the practitioners who are involved and their ideas and worldviews, they base their problem-framing on the judgement of what is relevant, thus referring back to the discursive power involved in actor selection and construction. In this context, the PI of an urban development project reflected on how involving different associations into research is part of a political environment, shaping the core of the research agenda in important ways:

When you join them at work, we are seen as revanchists and reactionary and with others, when we work together with them, we are regarded as neo-Marxist revolutionaries (DR1b).

The discursive power inherent to judging the relevance of an issue is traceable in the normative positions of researchers and practitioners regarding sustainability. Depending on the context and types of actors involved, powerful societal discourses frame the agenda and problem-solving approach chosen. For example, interviewees participating in a project on sustainable technologies involving private sector actors expressed the need for sustainability solutions to be compatible with economic growth (ER1, EP1, EP2). As the PI argued:

We really want to develop business models together with the companies, where they continue to have good returns, where they can continue to work profit-orientated, because otherwise it will not work, when you talk about zero-growth-society. Because we think otherwise the companies will disregard it and without them nothing will change (ER1).

The interviewed private sector practitioners also identified the requirement for the problem-solving approach to be compatible with economic principles, thus allowing for profit-making (EP1, EP2). Using discursive power, dominant ideas external to the TD project were reproduced in the collaboration process and framed the overall research agenda.

While researches and practitioners in the above project shared the same vision of sustainability, which

Table 5 WHAT: forms of power exercised by funding body, researchers, and practitioners

\begin{tabular}{|c|c|c|c|}
\hline $\begin{array}{l}\text { WHAT: power in } \\
\text { agenda setting }\end{array}$ & Funding body & Researchers & Practitioners \\
\hline Instrumental & - & $\begin{array}{l}\text { Setting the research agenda in the research } \\
\text { proposal; based on their authority as project } \\
\text { leaders, their knowledge about proposal } \\
\text { writing, and their financial/time resources; } \\
\text { setting topics on workshop and meeting } \\
\text { agendas }\end{array}$ & - \\
\hline Structural & $\begin{array}{l}\text { Setting the relevance of research } \\
\text { agendas for sustainable development } \\
\text { as precondition for funding; based on } \\
\text { material-structural sources }\end{array}$ & - & $\begin{array}{l}\text { Filtering topics which are considered } \\
\text { relevant and manageable/having } \\
\text { chances of implementation; based on } \\
\text { their position as legitimate and } \\
\text { knowledgeable actors as well as } \\
\text { potential implementers; silent or } \\
\text { outspoken threat of not participating } \\
\text { if agenda is not adapted }\end{array}$ \\
\hline Discursive & $\begin{array}{l}\text { Framing the kind of agendas worthy } \\
\text { of funding, referring to 'scientific } \\
\text { excellence' and 'societal relevance/ } \\
\text { contribution' }\end{array}$ & - & $\begin{array}{l}\text { Framing sustainability understanding } \\
\text { underpinning the agenda, reproducing } \\
\text { discourses about pathways to sustainable } \\
\text { futures; constructing practitioners as the } \\
\text { actors capable of defining what is relevant } \\
\text { and useable; activating ideals of 'moving } \\
\text { out of the ivory tower', 'giving something } \\
\text { back', 'balance of giving and taking' }\end{array}$ \\
\hline
\end{tabular}


shaped their perceptions both of the issue and possible solutions, perspectives diverged in other cases. Such situations reveal the powerful position of practitioners in making their values count in agenda setting (BR2, BR3). In a project on regional development and the role of the built environment, two interviewed researchers argued that the practices of the public sector actors involved in the project were inherently unsustainable due to the entailed land use and mobility practices. However, despite the clear divergence from the researchers' understanding of sustainability, both stated that they refrained from voicing this fundamental criticism to the practitioners and kept certain sensitive issues off the agenda due to their fear of scaring off the participating policymakers (BR2, BR3) (Table 5).

\section{HOW: power in rule setting and contestation}

The analysis of procedures of participation illuminates the capacity of the three groups of actors to set the terms of interactions and define 'the rules of the game'. The exercise of power in rule-setting includes the timing of interaction, the design of formats, and the norms that govern the participation process.

\section{Funding body}

The funding body appears in researchers' narrations as a distant actor pre-determining the rules of participation. This perception of the power of the funding body is notably evinced in narrations about the rules according to which financial resources are allocated to researchers and practitioners (BR1, BR3, DR1b, ER1, ER2). For example, one researcher described the funding structures being such that 'traditional' scientific projects were called for:

Well, that was predetermined by the funding body, it is a really, a purely scientific project. No practitioners are directly involved, like for example in other programmes [name of programmes], who make some own contribution or co-finance the project; there you are tied to the funding body, so to speak. (...) But now you cannot influence it with this funding scheme (ER1).

This researcher interpreted the role of the funding body as setting the rules of interaction and structural conditions shaping their own behavioural options. The funding call does not mention the possibility of applying for funding for practitioners (funding call 2014,15). Hence, while not explicitly prohibiting financial compensation of practitioners, neither does it incentivise accounting for them in the budget plans. Accordingly, in only one project did both the interviewed researcher and practitioner mention financial resources provided for the latter in the form of a part-time employee's salary (CR2, CP1). Whereas various researchers perceived the unequal distribution of financial resources built into the funding programme as undermining their goals of co-creation and collaborating on equal footing (BR1, BR2, DR1b, DR2), practitioners' reflections on the role of financial resources were ambivalent. The lack of financial support was particularly problematized by interviewees from third sector organisations (DP1, DP2), who struggled with precarious financial situations, whereas public service and private sector actors did not perceive their capacities to engage to be circumscribed by a lack of material sources (BP1, BP2, BP3, EP1, EP2). Rather than financial resources for participating in the process, the latter emphasised the provision of resources for implementing outputs.

\section{Researchers}

Even though the funding call uses 'transdisciplinarity' as a framing concept and refers to it in the very first paragraph (funding call 2014,15), it remains vague regarding the desired form of practitioner involvement and delegates the authority to set the rules of involvement to the project leaders. Across the five projects, the instrumental rule-setting power lay with the researchers. By means of their role as legitimate project authorities entitled by funding contracts and equipped with the necessary knowledge for developing and conducting research projects, they regulated the procedural formats of participation. Formal co-leadership with practitioners that would endow practitioners with rule-setting power was not practised in any of the projects.

Accordingly, in narrations across projects, researchers appear as the prime actors when it comes to setting the formats of interactions, planning of interactive events, selection of methods used to structure the interaction, and determining meeting locations (AR2, BR2, BR3, ER1, ER2). Likewise, the timing of interactions and the structuring of time schedules constitute powerful means of influencing the process. With few exceptions, the timing of interactions was determined by the researchers in accordance with their research schedules. Several practitioners perceived the exchange as driven by researchers' demands (BP2, BP3, DP1, DP2). Statements such as 'when from the perspective of the university there is reason to meet' (BP2) or 'when it is time for feedback' (AR2) indicate that the researchers determined when and on which occasions to meet and how to involve practitioners. While most practitioners did not problematize the control of time plans by researchers, one interviewee perceived his lack of information on what should happen when to hamper his involvement (DP2). Reflections on the setting of timing and formats of interaction unveil the discursive power of norms and perceived structural constraints related to wider temporalities in both the academic and practice contexts. Externally set project durations determined by the funding 
body (DR1b, ER2) and the 'projectification' of work in the third sector (DR1b, DP2) were critically evoked, and a synchronicity problem between research and practice (DP2) was perceived to confine the participants' behavioural options.

For some researchers, decision-making and rule setting in a TD context meant sharing control of the process with practitioners. They referred to ideal principles such as engaging on 'equal footing' and at 'eye level' (BR1, BR2, CR2, DR1b, DR2, DP1). However, this sharing of control was not formalised in the decision-making structures of the five projects (AR2, AR3, AR4, BR2, BR3, ER1, ER2). The following researcher experienced this situation as a loss of control:

And yes, therefore my interim assessment is in the end: it is frighteningly challenging, and you must just put up with a lot and also accept it as it is and not try to change it according to your own ideas [....] Well, some interesting experience to work with practitioners, because, no matter how well you are prepared, you have a totally uncontrollable part in the whole thing (DR2).

Only in the project in which financial resources were allocated to a selected practitioner did interviewees from research and practice recall how they jointly set the formats used in workshops and meetings. Based on the practitioners' reactions, adaptations are made to the rules $(\mathrm{CP} 1)$. While the practitioner in this project is involved in rule setting because her context knowledge allows her to judge whether the approach fits the local circumstances, the organisational decisions are nonetheless adapted to the professor, who indirectly influences rule setting. Inversely to examples discussed in the other projects, the practitioner explained that they set the dates and adapted their time plans to the availabilities of the PIs and professors (CP1). Concomitantly, the researcher managing the TD case restricted other researchers' access to the case in order to keep it functional. As she asserted, involving more people in setting rules and taking process-related decisions requires more time, thus illuminating a perceived trade-off between diversity and functionality (CR2). The following extract relates to power in so far as involving fewer people in setting rules and taking decisions allows for greater control and influence over the interactions:

$[\mathrm{M}]$ ore diversity would have been a lot more beneficial, of different people, minds; at the same time, it's a matter of focus what I could have done because diversity and co-creation processes and decisions on process, just how to get by with something, equals time (CR2).
Regarding participation in knowledge production, the negotiation and contestation of rules governing the process appear as exercises of power in which discursive formations are crucial. Interviewees from both groups narrated moments in which they renegotiated the rules of interactions. Such situations reveal tensions of engaging in TD processes (AR2, AR4, DP2). In their attempts to influence the rules of interactions, actors mostly relied on ideational sources such as norms and values regarding the appropriate relationship between research and practice. Three researchers from a project in the field of health and education recalled a conflictual situation in which a practitioner's attempt to erase questions from a survey resulted in their defence of scientific freedom (AR2, AR3, AR4) - an act of rule assertion. In this context, the researchers' discursive power mobilised widely acknowledged norms of good scientific practice and was rooted in their perceived legitimacy and selfconception as the actors in charge of setting the research approach. In reaction to a perceived attack on these norms, one researcher repeatedly stressed that a clear boundary with the practitioners was drawn when developing the data collection instruments because data collection needs to be a 'one-way street' (AR2). Her argumentation uncovers that the practitioners, in this case public service providers, are invited to participate in temporarily delimited ways. Asked about how the researchers deal with the practitioners' attempts to bend the rules of data collection practices, this researcher drew boundaries in order to preserve what she considered good scientific practice:

Because otherwise we move into an area where it becomes consultancy work, and that doesn't work that way. [...] We try to find a diplomatic way, but it is not that easy to meet everyone's interests. I think we are in a negotiation position to say, if you do not accept our way of doing it, then we can't realise it in [your institution]. Because I think that would be the end of any scientific institution, if we let them dictate the questions of our survey (AR2).

In her perception, the researchers are in a strong 'negotiation position' to defend their interests, because as a last resort they can replace the practitioners by others-this is a position that she was convinced was supported by the PI. In this context, threating to end the collaboration-which was previously identified as a mechanism for practitioners to steer the process and its content-was used as an exercise of the researcher's power and relates to their perception of the practitioners as being 'exchangeable' (AR2). 


\section{Practitioners}

While researchers across the five projects were authorised as official project actors to set the rules, practitioners indirectly influenced rule setting or affected the procedures of participation through their decisions, thus emphasising the necessity of looking beyond formal decision-making when analysing power relations. Due to a perceived dependence on the continuous participation of practitioners, in setting the rules and terms of interaction, researchers strove to anticipate and accommodate the (imagined) preferences of practitioners, whether regarding locations (ER2), time schedules (ER1, ER2), or methods (BR2, CR2 ER1, ER2). In doing so, they set up the process such that it allegedly satisfied practitioners and complied with their habitual ways of collaborating. Thus, practitioners indirectly wield structural power over the setting of rules. The following reflection exemplifies how the researcher perceived a threat of losing needed practitioners, which affected the researcher's behaviour in subtle ways and resulted in her relaxing and adapting some rules:

I let a lot of flexibility, also trying to somehow compensate for their lack of commitment and accountability a bit. So, when I felt that they were not so committed, then I made it more flexible for them. And now I would probably, I would be more discipline[d] with them and say 'I expect this and this from you', 'deliver!', no [Laughing] (CR2).

How practitioners indirectly influence the rules of the participation process through their decisions becomes even more tangible when looking at data collection practices and researchers' field access. Practitioners' exercise of structural power rests on their position in the respective practice context in which they are perceived as the ones legitimised to take decisions. In collaborations with politicians and policymakers, this legitimacy is linked to their democratic legitimacy. Similar observations were made for practitioners who were not representative for the field or legitimised to speak on behalf of others. In these cases, their exercise of power rested mainly on their access to networks and the projects' target groups (AR2, BR2 CR2, ER1, ER2) as well as potential beneficiaries and multipliers of its outputs (AR3, AR3, AR4). This position in the practice context allowed them to mobilise further actors to engage with the project or its outputs. Their decisions to facilitate or complicate the data collection-such as the dissemination of surveys-affect the TD process. Practitioners across the projects explained that they approved data collection tools (AP1, BP1, BP2, BP3) or assumed the role of respondents themselves (DP1, DP2, EP1, EP2) in the case of both qualitative and quantitative approaches. Thus, they tacitly influenced the knowledge production process and shaped inputs into the research process. Being authorised by the practitioners and giving authorisation, respectively, likewise appears in researchers' narrations (AR2, AR3, AR4, BR2, BR3, ER2).

Taking up the previously mentioned conflict about data collection in a practice institution exemplifies how rules of data collection are contested by both actor groups, thus illustrating the back and forth shifting nature of power. Researchers of one project recounted how the involved public service provider prevented them from doing participatory observations and tried to

Table 6 HOW: forms of power exercised by funding body, researchers, and practitioners

\begin{tabular}{|c|c|c|c|}
\hline $\begin{array}{l}\text { HOW: power } \\
\text { in rule } \\
\text { setting }\end{array}$ & Funding body & Researchers & Practitioners \\
\hline Instrumental & - & $\begin{array}{l}\text { Setting the rules, formats, and timing of } \\
\text { participation; based on their authority as } \\
\text { project leaders as well as their financial } \\
\text { and time resources }\end{array}$ & - \\
\hline Structural & $\begin{array}{l}\text { Shaping the rules of resource allocation among } \\
\text { researchers and practitioners and of project } \\
\text { (co-leadership (not involving practitioners); } \\
\text { based on material sources shaping the structural } \\
\text { conditions and the procedural options of the } \\
\text { actors involved }\end{array}$ & $\begin{array}{l}\text { Silent or outspoken threat of ending } \\
\text { collaboration due to actors' disrespect } \\
\text { of rules or refusal to adapt rules; keeping } \\
\text { practitioners away from certain activities } \\
\text { (e.g., data collection); based on their } \\
\text { authority as project leaders and their } \\
\text { legitimacy as researchers }\end{array}$ & $\begin{array}{l}\text { Silent or outspoken threat of withdrawal } \\
\text { due to actors' disrespect of rules or refusal } \\
\text { to adapt rules; shaping the terms of } \\
\text { researchers' entering the field, access to } \\
\text { data or actors in the field; based on their } \\
\text { legitimacy in the field and their actor } \\
\text { networks }\end{array}$ \\
\hline Discursive & $\begin{array}{l}\text { Referring to 'transdisciplinarity' as an ideal of } \\
\text { how researchers and practitioners should } \\
\text { interact }\end{array}$ & $\begin{array}{l}\text { Referring to 'equal footing' as an ideal of } \\
\text { how researchers and practitioners should } \\
\text { interact, questioning clear-cut boundaries } \\
\text { between research and practice; referring } \\
\text { to norms of 'good' scientific practice to } \\
\text { reinforce rules }\end{array}$ & $\begin{array}{l}\text { Referring to/upholding division of labour } \\
\text { between research and practice as ideal }\end{array}$ \\
\hline
\end{tabular}


influence survey questions, ${ }^{7}$ thus delimiting the space of interaction (AR2, AR3, AR4). Besides restricting certain forms of data collection, the practitioners shaped rules on its timing and organisation; researchers were asked not to repeatedly bother employees, but rather to combine data collection activities. In such situations, the practitioners' structural power lies in their decision authority regarding any activities in their institution and in the silent threat of withdrawing from the project. In the researchers' interpretation, the circumstance that a presumably sensitive topic is to be investigated and the practitioners' fear to be evaluated leads them to contest the rules, i.e., keeping researchers away from activities that they consider to be sensitive (AR2, AR4). The practitioners exercise structural power by delimiting the researchers' access to their institutions, which allows them to keep certain issues off the agenda. In their role as 'gatekeepers'- which several researchers ascribed to their practitioners (AR2, BR2 CR2, ER1, ER2), they control researchers' access to the field (Table 6).

\section{Discussion and conclusions}

This article aimed at understanding how power is exercised in participation practices in TD sustainability research. For this purpose, it proposed and empirically applied a theoretical framework that links three dimensions of power (instrumental, structural, discursive) to three elements constituting participation (subjects, objects, procedures). The analysis of five TD projects-all part of the same sustainability-orientated funding programme-has shown that the three elements of participation practices each provide important, albeit interrelated entry points for the exertion of power in defining the actors, their roles, and respective positioning as well as in setting the research agendas and rules governing their interactions (Additional file 1: Table S1). In this section, we discuss the empirical findings in regard to the theoretical framework presented and to ideals of TD research. We highlight the interplay and simultaneity of dimensions of power and the context embeddedness of sources of power and reflect on the implications of our findings for research practice and governance.

\section{The interplay and simultaneity of different dimensions of power}

In this article, we have shown that TD interactions of researchers and practitioners are pervaded by an interplay of different dimensions of power. The diverse manifestations of power identified in our analysis (Tables 4, 5, 6) illuminate discrepancies between the ideals of TD of shared control, ownership, and co-leadership [11, 12]

\footnotetext{
${ }^{7}$ The researchers described how they then relied on power of reframing their activity in order to lower the resistances of the practitioners regarding such methods (AR2, AR4).
}

and actual practices in the five projects. Firstly, focusing on formal decision-making and the most visible form of power in its instrumental usage, researchers appeared as powerful actors across all three constitutive elements of participation. This interpretation supports previous findings on the powerful role of researchers in initiating and controlling TD as well as corresponding power asymmetries among researchers and practitioners [24, 30, 31]. Mapped on the continuum between consulting and participatory TD, four of the five projects (with slightly varying distances) would appear closer to the 'consulting' than the 'participatory' end of the spectrum [36].

Secondly, applying the multidimensional conceptualisation of power underpinning our analysis reveals that looking at the exercise of instrumental power manifested in the abovementioned power asymmetries provides only a partial picture. A consideration of structural and discursive power as well as instrumental forms illuminates the funding body's and the practitioners' influence on actor selection, agenda setting, and rule setting. The different actors' exercises of power uncovered a relational interplay of power between the funding body, the researchers, and the practitioners, thus revealing a more nuanced picture of power dynamics. By prescribing the kinds and ranges of project leadership, resource allocation, and topical foci, the funding body wielded structural and discursive power over participation practices in the projects. Given these structural conditions, by way of the authority transferred to them as project leaders, researchers simultaneously wielded instrumental power over the (pre-)selection of actors, the setting of the agenda, and the rules of interaction. However, situations of shifting power relations between researchers and practitioners and an interplay of different dimensions of power were exposed. Across the three elements of participation, the decisions of practitioners were influential and, in some cases, strongly impacted the process. Their influence became particularly tangible in their threats to withdraw or actual withdrawal from the process as well as in the contestation of rules, most notably regarding researchers' field access. Such exercises of instrumental and structural power were intertwined with the conditions prescribed by the funding body, which resulted in largely non-formalised collaborations and a limited accountability of practitioners. Moreover, the simultaneous exercise of discursive power by researchers and practitioners shaped the ascription of roles, largely upholding a traditional division of labour between those producing and those using knowledge.

These findings across the three elements of participation stress the need for a nuanced view on power relations that extends beyond dichotomies and binary conceptions of 'the powerful' and 'the powerless' actors in participation practices and their conceptual representations [19]. The 
need for more nuanced actor understandings is also reflected in the circumstance that practitioners do not problematize the described dominance of researchers. Unlike implicit to TD ideals of shared control $[12,13]$, practitioners in the projects analysed herein did not necessarily want to play any decision-making roles or assume responsibility for the entire process [75] — not only due to a lack of financial resources, but also because the observed division of labour between researchers and practitioners aligned with their epistemological values regarding appropriate science-society relations. Since previous studies have established direct links between inequalities in funding structures and the lack of ownership for the process and conclude that the provision of financial resources will correct this shortcoming [38], it remains to be investigated to what extent our findings are sensitive to the type of practitioner as well the specificities of the funding context.

Assessing the funding body, researchers, and practitioners may support the recognition and reinterpretation of different actors' influence over the process. Such reinterpretations are especially relevant if we follow Kanter's reflections [76] that power perpetuates power and powerlessness perpetuates powerlessness, thus suggesting that actors' behaviour is influenced by their assumptions about their own and others' power. We concur with Purdy ([54], p., 415) that a multidimensional examination of power can uncover 'mistaken beliefs and hidden sources of power that may reduce overconfident, defensive, or domineering behaviours' also in TD research, in which-according to self-proclaimed goals and design principles of egalitarian interactions-the use of power might be unintentional.

\section{Context embeddedness of sources of power}

Our findings show that in their exercise of power the funding body, the researchers and practitioners relied on diverse sources, including financial and time resources and networks (material sources), authority, legitimacy in relation to norms and values, and knowledge (ideational). Contrary to our expectation, expertise and knowledge were only marginally addressed as sources of power in our empirical material. Considering that TD scholars have widely argued for expertise to be the main criterion for involvement in TD and knowledge generation to be its main goal [77], this counterintuitive finding requires further investigation. One possible explanation relates to our observation that researcher-practitioner interactions often took place in clearly delimited spaces and sub-projects primarily designed to accomplish transformational goals rather than knowledge production goals.

Our analysis of actors' ideational and material sources of power unveiled the importance of the different contexts. Firstly, in support of earlier findings [29, 31, 34], the study exposed the powerful role of funding bodies in shaping the behavioural options of researchers and practitioners and showed how ambiguous or partly incoherent signals built into the programme script affected actors' sources of power-in this case, calling for participation without adapting funding mechanisms accordingly. Secondly and closely linked to the funding context, a few sources of power, such as the authority of project leaders, as well as norms and ideals of how TD processes should be (e.g., on equal footing, moving out of the ivory tower, a win-win for all participants) reside in the immediate project context. Thirdly, most sources of power are embedded in the wider context (Fig. 1); they stem from the practitioners' position in the practice context, e.g., their decision authority or legitimacy therein, as well as the researchers' position in the academic context and their status as knowledge authorities. Thus, they relate to established norms regarding the appropriate relation between research and practice which-when perceived to be in tension with TD-can undermine the exercise of power.

The context embeddedness of sources of power manifested particularly regarding agenda setting. Since the funding programme required research agendas to be relevant for sustainability transformations, they were inherently normative, value-laden, and contested [9]. Due to their position in the practice context, practitioners in the five projects appeared as the legitimate actors to judge which issues-albeit mostly pre-selected by the researchers-were relevant to be placed on the agendas of sub-projects. Due to their authority to implement decisions in the practice context, they appeared as the legitimate figures to judge which solutions were worth pursuing. What is perceived to be worth researching or developing relates to whose values count and where the power to realise them is located [78]. In thus shaping which futures are considered desirable or even possible and plausible [79], participation practices within TD projects may shape socio-political developments in the practice context (twoway interactions as depicted in Fig. 1). This transfer of actors' power in the practice context into TD projects runs the risk of reproducing dominant societal discourses in agenda setting, rather than breaking loose of them. Concomitantly, it risks marginalising less visible and powerful ideas and actors, thus jeopardising the transformative potential of TD [10].

Context embeddedness also crystallised in the influence of distant actors on the process and its subjects. Powerful actors in the practitioners' networks influence their participation and can in extreme cases prompt their withdrawal by revoking authorisation. Power regarding the composition of actors relates not only to this wider context, but also needs to be seen in the sense of objects and procedures within the project. That subjects, objects, and procedures of participation are co-produced [21] is supported by findings on agenda setting. Not only 
did the actor constellation shape which issues were put on the agenda, but the agenda also affected the actor composition. Depending on whether the agenda is perceived as truly relevant or at least not harmful to practitioners' interests, the actor constellation may change. Furthermore, the negotiation or contestation of rules and procedures of participation was identified as a strategy of keeping sensitive issues off the agenda and limiting the kinds of actors, opinions, or discourses that are rendered visible in the practice context. Thus, power in agenda setting can only be understood in the context of the subjects and procedures of participation and requires reflexivity in order to prevent the instrumental circumscription of issues previously identified for participatory technology appraisals [80]. This example also illustrates how the three components of participation interact and power-strewn path depend decisions can occur throughout TD projects.

Overall, the context embeddedness of power sources urges us to understand participation practices in TD projects as situated in the wider socio-political context and predominant science-society relations $[19,25]$. Power constellations within TD projects vary according to the prevailing knowledge hegemonies and hierarchies in the socio-political context as well as the dominant knowledge regimes and value orders entrenched in the academic context [34]. Thus, our analysis reinforces previous calls for considering both structure and agency in order to understand power dynamics in TD settings [23].

\section{Implications for research practice and governance}

The exercises of power identified in this article give guidance for future (self-)reflexive processes to researchers and practitioners engaging in TD practices as well to funding bodies and science institutions calling for TD and co-creation processes.

For researchers, such an assessment provides not only the opportunity for reflexivity about their own powerful roles, but also can assist in unveiling the effects of nonformalised or weakly formalised collaborations with practitioners. In these constellations, instrumental power lies predominantly with one actor group; however, responsibilities and accountabilities are also likely to be unequally distributed. Accounting for power dynamics is useful for illuminating their potential dependencies on practitioners throughout the process and communicating and planning accordingly, thus enabling researchers to reduce their vulnerabilities to the risk of practitioners withdrawing from the process. For both researchers and practitioners, identifying the sources of power on which they rely in order to shape the TD process can help to steer or counterbalance power dynamics, i.e., by deliberately creating these sources. Moreover, reflexivity regarding the discursive power exercised by practitioners enhances awareness of the kinds of societal discourses and structures that the TD project potentially stabilises or transforms. An analysis of 'power over', as suggested by Table 1, can serve as a basis for explorations of the potential of projects to unleash transformative power (e.g., 'power to' and 'power with').

For funding bodies, an assessment of the structural and discursive forms of power exercised through the funding regulations is particularly relevant. Funders are in a key position to transform norm systems in research practice and governance [29]. A power analysis such as illustrated in Table 1 can be useful to assess whether the programme goals are coherently reflected in the funding structures and whether these are conducive to the kinds of research processes the funding body wants to promote. If the funder aims to realise the ideals of TD, including shared ownership and responsibility, then co-leadership as well as-depending on the type of practitioners-the provision of financial means can provide critical sources of power that partly countervail asymmetries.

Similar conclusions can be drawn concerning the implementation and design of agenda-setting processes. The power analysis along the dimensions suggested in Table 1 provides insights into challenges and barriers of participatory agenda-setting processes in research. Being sensitive to power relations in agenda setting requires those initiating the process to be reflexive and transparent about how their pre-selection of issues and the rules governing the processes result in the inclusion of some and exclusion of other values and knowledge. They should be aware that within the frameworks set by the governing actors, hidden power dynamics unfold during the processes and require continuous reflection in order to ensure robust outcomes.

\section{Limitations and future research}

While a meta-analysis of power as performed in this article produces valuable insights into the diverse manifestations of power, its analytical scope remains partial. The meta-analysis and aggregation of findings were done such that it enabled the mapping of the diversity of power exercised by three types of actors in five projects while ensuring the anonymity of interviewees and projects. Consequently, the specificities and situatedness [55] of the actors and processes could only be addressed to a limited extent. In addition to analyses of power in researcher-practitioner interactions, similar analyses of power within both actor groups are needed to draw a more holistic picture of power in TD research. Observations in our empirical material about power relations among researchers, such as the powerful roles of knowledge brokers and intermediaries and the corresponding 'responsibilisation' of a few individuals [14] at the research-practice interface as well as among 
practitioners could not be exploited. Within the heterogeneous group of practitioners, we saw actor differences with regard to whether project-based financial resources appeared as a necessary source of power for practitioners. While NGOs and associations tended to see them as a prerequisite to ensure egalitarian interactions and practitioners' capacities to influence the process, interviewees from the private and public sectors less so felt their power over the participation process circumscribed by a lack of financial resources. At the same time, it seems, the equation of being powerful in the practice field equals power within the TD process seems oversimplified. The researchers identified strong dependencies also on practitioners such as NGOs and associations which might not have been the most powerful players in the practice field, but which were irreplaceable with regard to achieving the project-specific goals. The heterogeneity of actors within the broad groups thus warrants further attention. Moreover, the presented findings are context-bound to one funding programme in the global North and should be compared and complemented with analyses from other settings.

Although the tripartite differentiation of instrumental, structural, and discursive forms of power provided useful analytical categories and enabled a clarification of the diverse manifestations of power in our empirical data, their malleable and fluid character should be noted. Moreover, because power is relational and shaped by interaction, the static depictions in Tables 1, 4, 5, and 6 are limited in their ability to fully account for power dynamics as well as for path dependencies throughout TD projects. The latter might manifest, for example, if the terms of participation are largely pre-determined by the funder. In such a case, there is arguably diminished scope for other actors to exercise power at each of the three entry points identified in this article (subjects, objects, procedures). The methods applied and our own positionality in an accompanying research project to the funding programme limited the extent to which dynamics in everyday research practices could be grasped. Despite the fact that data collection took place at multiple times during the on-going projects, only snapshots of steadily evolving projects could be taken. Hence, actor dynamics over time were primarily accessed based on interviewees' perceptions and narrations. Some of the tacit dynamics related to power necessitate further empirical research based on a diverse methodological repertoire, including participatory observations and an assessment of project outputs with regard to whose knowledge and values are captured in them. The power and participation framework used in this article can be applied for future studies to conduct multiple analyses over the course of a TD project, thereby examining how power dynamics and perceptions thereof change and/or are cemented.
Examining the very practice of participation through a power lens opens up avenues for critical sustainability and future-orientated studies that are sensitive to power dynamics and reflexive toward their own practices. We hope to incite TD sustainability scholars to share their experiences with power within TD knowledge production processes and build a practice-related knowledge base on diverse facets of power. Such a knowledge-base will also enhance our understanding of which kinds of power structures hamper joint knowledge production and problem-solving and which structures leverage the potential of reaching knowledge production and transformational goals of TD research.

\section{Supplementary information}

Supplementary information accompanies this paper at https://doi.org/10. 1186/s40309-020-0161-4.

Additional file 1: Table S1. Overview of findings per form of power,

participation component and actor

\section{Abbreviations}

NGO: Non-governmental organisation; PI: Principal investigator; SME: Small and medium enterprise; TD: Transdisciplinary

\begin{abstract}
Acknowledgements
The authors thank all researchers and practitioners of the five sustainability research projects for sharing their experiences and thoughts. They furthermore thank Silvia Hostettler, Michael Hutter, and Albert MerinoSaum as well as two anonymous reviewers for their helpful and constructive comments on this manuscript.
\end{abstract}

\section{Authors' contributions}

This research was designed, carried out, and written principally by LF. LF developed the conceptual perspective, collected the empirical data, and performed the analysis. CRB supported the interpretation of findings. All authors read and approved the final manuscript.

\section{Authors' information}

Livia Fritz, studies in development studies and political science at the University of Vienna (Austria) and the Institut d'études politiques de Paris (France); previously junior research at the Austrian Foundation for Development research and the University of Munich (Germany); currently doctoral assistant at the Laboratory for Human-Environment Relations in Urban Systems at EPF Lausanne (Switzerland); research interests: interlinkages between research, policy-making, and societal change in the field of sustainability; discourses and practices of participation in knowledge production; science policy.

Prof. Dr. Claudia R. Binder, studies in biochemistry, doctorate, and habilitation in environmental sciences at ETH Zurich, Switzerland. Since March 2016 head of the Laboratory for Human-Environment Relations in Urban Systems and Swiss Mobiliar Chair for Urban Ecology at École Polytechnique Fédérale de Lausanne (EPFL), Switzerland. Research interests: analysing, modelling, and assessing sustainability transitions of urban systems.

\section{Funding}

This research is funded by the Ministry for Science and Culture of Lower Saxony, Germany.

Availability of data and materials

For reasons of anonymisation, the empirical material is not available.

Ethics approval and consent to participate

All interviewees in the study gave their informed consent to participate. 


\section{Consent for publication}

Not applicable.

\section{Competing interests}

The authors declare that they have no competing interests.

Received: 6 August 2019 Accepted: 13 January 2020 Published online: 24 February 2020

\section{References}

1. United Nations (2015) Transforming our world: the 2030 agenda for sustainable development, A /RES/70/1. New York

2. Schneider F, Kläy A, Zimmermann AB, Buser T, Ingalls M, Messerli P (2019) How can science support the 2030 Agenda for Sustainable Development? Four tasks to tackle the normative dimension of sustainability. Sustainability Science 14:1593. https://doi.org/10.1007/s11625-019-00675-y.

3. Hoppe R (1999) Policy analysis, science and politics: from 'speaking truth to power' to 'making sense together'. Sci Public Policy 26:201-210. https://doi. org/10.3152/147154399781782482

4. European Commission (2019) Horizon 2020 - work programme 2018-2020. Science with and for Society. Decision C(2019)1849 of 18 March 2019. http://ec.europa.eu/research/participants/data/ref/h2020/wp/2018-2020/ main/h2020-wp1820-swfs_en.pdf

5. Schneider F, Buser T, Keller R, Tribaldos T, Rist S (2019) Research funding programmes aiming for societal transformations: ten key stages. Sci Public Policy 46:463-478. https://doi.org/10.1093/scipol/scy074

6. Van der Hel S (2016) New science for global sustainability? The institutionalisation of knowledge co-production in Future Earth. Environ Sci Pol 61:165-175. https://doi.org/10.1016/j.envsci.2016.03.012

7. Gudowsky N, Sotoudeh M (2017) Into blue skies—a transdisciplinary foresight and co-creation method for adding robustness to visioneering. NanoEthics 11:93-106. https://doi.org/10.1007/s11569-017-0284-7.

8. de Jong SP, Wardenaar T, Horlings E (2016) Exploring the promises of transdisciplinary research: a quantitative study of two climate research programmes. Res Policy 45:1397-1409. https://doi.org/10.1016/j.respol.2016. 04.008.

9. Polk M (2014) Achieving the promise of transdisciplinarity: a critical exploration of the relationship between transdisciplinary research and societal problem solving. Sustain Sci 9:439-451. https://doi.org/10.1007/ s11625-014-0247-7

10. Marshall F, Dolley J, Priya R (2018) Transdisciplinary research as transformative space making for sustainability: enhancing propoor transformative agency in periurban contexts. Ecol Soc 23. https://doi.org/10. 5751/ES-10249-230308

11. Scholz R, Steiner G (2015) The real type and ideal type of transdisciplinary processes: part II-what constraints and obstacles do we meet in practice? Sustain Sci 10:653-671. https://doi.org/10.1007/s11625-015-0327-3

12. Lang DJ, Wiek A, Bergmann M, Stauffacher M, Martens $P$, Moll $P$, Swilling $M$, Thomas CJ (2012) Transdisciplinary research in sustainability science: practice, principles, and challenges. Sustain Sci 7:25-43. https://doi.org/10. 1007/s11625-011-0149-x

13. Luthe $T$ (2017) Success in transdisciplinary sustainability research. Sustainability 9:71. https://doi.org/10.3390/su9010071

14. Maasen S, Lieven O (2006) Transdisciplinarity: a new mode of governing science? Sci Public Policy 33:399-410. https://doi.org/10.3152/ 147154306781778803.

15. Stauffacher M, Flüeler T, Krütli P, Scholz RW (2008) Analytic and dynamic approach to collaboration: a transdisciplinary case study on sustainable landscape development in a Swiss prealpine region. Syst Pract Action Res 21:409-422. https://doi.org/10.1007/s11213-008-9107-7

16. Arnstein SR (1969) A ladder of citizen participation. J Am Inst Plann 35:216-224

17. Avelino F (2017) Power in sustainability transitions: analysing power and (dis)empowerment in transformative change towards sustainability. Environ Policy Gov. https://doi.org/10.1002/eet.1777

18. Grunwald A (2013) Modes of orientation provided by futures studies: making sense of diversity and divergence. Eur J Futures Res 2:30. https://doi. org/10.1007/s40309-013-0030-5

19. Fritz L, Binder CR (2018) Participation as relational space: a critical approach to analysing participation in sustainability research. Sustainability 10:2853. https://doi.org/10.3390/su10082853
20. Klenk NL, Meehan K (2017) Transdisciplinary sustainability research beyond engagement models: toward adventures in relevance. Environ Sci Pol 78: 27-35. https://doi.org/10.1016/j.envsci.2017.09.006

21. Chilvers J, Pallett $H$, Hargreaves T (2018) Ecologies of participation in sociotechnical change: the case of energy system transitions. Energy Res Soc Sci 42:199-210. https://doi.org/10.1016/j.erss.2018.03.020

22. Nowotny H, Scott P, Gibbons M (2001) Re-thinking science: knowledge and the public in an age of uncertainty. SciELO Argentina. p. 211.

23. Bréthaut C, Gallagher L, Dalton J, Allouche J (2019) Power dynamics and integration in the water-energy-food nexus: learning lessons for transdisciplinary research in Cambodia. Environ Sci Pol 94:153-162. https:// doi.org/10.1016/j.envsci.2019.01.010

24. Rosendahl J, Zanella MA, Rist S, Weigelt J (2015) Scientists' situated knowledge: strong objectivity in transdisciplinarity. Futures 65:17-27. https:// doi.org/10.1016/j.futures.2014.10.011

25. Schmidt L, Neuburger M (2017) Trapped between privileges and precariousness: tracing transdisciplinary research in a postcolonial setting. Futures 93:54-67. https://doi.org/10.1016/j.futures.2017.07.005.

26. MacMynowski DP (2007) Pausing at the brink of interdisciplinarity: power and knowledge at the meeting of social and biophysical science. Ecol Soc 12. https://doi.org/10.5751/ES-02009-120120.

27. Bieluch KH, Bell KP, Teisl MF, Lindenfeld LA, Leahy J, Silka L (2016) Transdisciplinary research partnerships in sustainability science: an examination of stakeholder participation preferences. Sustain Sci:87-104 https://doi.org/10.1007/s11625-016-0360-x

28. Pohl C, Rist S, Zimmermann A, Fry P, Gurung GS, Schneider F, Speranza Cl, Kiteme B, Boillat S, Serrano E (2010) Researchers' roles in knowledge co-production: experience from sustainability research in Kenya, Switzerland, Bolivia and Nepal. Sci Public Policy 37:267-281. https://doi.org/10.3152/030234210X496628

29. Benner M, Sandström U (2000) Institutionalizing the triple helix: research funding and norms in the academic system. Res Policy 29:291-301. https:// doi.org/10.1016/S0048-7333(99)00067-0

30. Raymond CM, Fazey I, Reed MS, Stringer LC, Robinson GM, Evely AC (2010) Integrating local and scientific knowledge for environmental management. J Environ Manag 91:1766-1777. https://doi.org/10.1016/j.jenvman.2010.03.023

31. Schmidt L, Pröpper M (2017) Transdisciplinarity as a real-world challenge: a case study on a North-South collaboration. Sustain Sci 12:365-379. https:// doi.org/10.1007/s11625-017-0430-8

32. Vilsmaier U, Engbers $M$, Luthardt $P$, Maas-Deipenbrock RM, Wunderlich $S$, Scholz RW (2015) Case-based mutual learning sessions: knowledge integration and transfer in transdisciplinary processes. Sustain Sci 10:563580. https://doi.org/10.1007/s11625-015-0335-3

33. Westberg L, Polk M (2016) The role of learning in transdisciplinary research: moving from a normative concept to an analytical tool through a practice-based approach. Sustain Sci 11:385-397. https://doi.org/10.1007/s11625-016-0358-4

34. Felt U, lgelsböck J, Schikowitz A, Völker T (2016) Transdisciplinary sustainability research in practice: between imaginaries of collective experimentation and entrenched academic value orders. Sci Technol Hum Values 1:732-761. https://doi.org/10.1177/0162243915626989

35. McKee A, Guimaraes MH, Pinto-Correia T (2015) Social capital accumulation and the role of the researcher: an example of a transdisciplinary visioning process for the future of agriculture in Europe. Environ Sci Pol:88-99. https://doi.org/10.1016/j.envsci.2015.02.006

36. Mobjörk M (2010) Consulting versus participatory transdisciplinarity: a refined classification of transdisciplinary research. Futures 42:866-873. https://doi.org/10.1016/j.futures.2010.03.003

37. Cundill G, Roux DJ, Parker JN (2015) Nurturing communities of practice for transdisciplinary research. Ecol Soc 20:22. http://dx.doi.org/10.5751/ES-075 80-200222.

38. Zingerli C (2010) A sociology of international research partnerships for sustainable development. Eur J Dev Res 22:217-233. https:/doi.org/10.1057/ejdr.2010.1

39. Fuchs D, Glaab K (2011) Material power and normative conflict in global and local agrifood governance: the lessons of 'Golden Rice'in India. Food Policy 36:729-735. https://doi.org/10.1016/j.foodpol.2011.07.013.

40. Partzsch L, Fuchs D (2012) Philanthropy: power with in international relations. Journal of political power 5:359-376. https://doi.org/10.1080/ 2158379X.2012.735114

41. Partzsch L (2015) Kein Wandel ohne Macht-Nachhaltigkeitsforschung braucht ein mehrdimensionales Machtverständnis. GAIA-Ecological Perspectives for Science and Society 24:48-56. https://dx.doi.org/10.14512/ gaia.24.1.10 
42. Fritz $L$, Meinherz F (2020) The politics of participatory sustainability assessments: An analysis of power. In: C. R. Binder, E. Massaro, R. Wyss (Eds.): Sustainability Assessment of Urban Systems. Cambridge: Cambridge University Press, 87-122.

43. Fuchs D, Di Giulio A, Glaab K, Lorek S, Maniates M, Princen T, Røpke I (2016) Power: the missing element in sustainable consumption and absolute reductions research and action. J Clean Prod 132:298-307. https://doi.org/1 0.1016/j.jclepro.2015.02.006.

44. Weber M (1972) Wirtschaft und Gesellschaft. 5. rev. Aufl, Tübingen 242

45. Dahl RA (1957) The concept of power. Syst Res Behav Sci 2:201-215

46. Gaventa J, Cornwall A (2008) Power and knowledge. In: Reason P; Bradbury $H$ (eds.) The sage handbook of action research: participative inquiry and practice, Sage, London, 172-189

47. Gaventa J (2006) Finding the spaces for change: a power analysis. IDS Bull 37:23-33

48. Bachrach P, Baratz M (1962) Two faces of power. Am Polit Sci Rev 56

49. Hayward CR (2000) De-facing power. Cambridge University Press, New York a.o

50. Lukes S (1974) Power: a radical view. Macmillan, London and New York

51. Digeser P (1992) The fourth face of power. J Polit 54:977-1007. https://doi. org/10.2307/2132105.

52. Foucault M (1977) Discipline and punish: the birth of the prison. Vintage Books, New York

53. Greenwald HP (2007) Organizations: management without control. Sage Publications, Los Angeles a.o.

54. Purdy JM (2012) A framework for assessing power in collaborative governance processes. Public Adm Rev 72:409-417. https://doi.org/10.1111/ j.1540-6210.2011.02525.x

55. Haraway D (1988) Situated knowledges: the science question in feminism and the privilege of partial perspective. Fem Stud 14:575-599. https://doi. org/10.2307/3178066.

56. Collins HM, Evans R (2002) The third wave of science studies: studies of expertise and experience. Soc Stud Sci 32:235-296. https://doi.org/10.1177/ 0306312702032002003

57. Harding S (1992) Rethinking standpoint epistemology: what is "strong objectivity?". The Centennial Review 36:437-470

58. Jasanoff S (2003) Technologies of humility: citizen participation in governing science. Minerva 41:223-244. https://doi.org/10.1023/A:1025557512320.

59. Schneidewind U, Augenstein K, Stelzer F, Wanner M (2018) Structure matters: real-world laboratories as a new type of large-scale research infrastructure: a framework inspired by Giddens' structuration theory. GAIAEcological Perspectives for Science and Society 27:12-17. https://doi.org/10. 14512/gaia.27.S1.5

60. Wolff S (2004) Analysis of documents and records. In: Flick U; von Kardoff E; Steineke, I (eds): A companion to qualitative research. Sage: London a.o. 284-289

61. Lincoln YS, Guba EG (1985) Naturalistic inquiry. SAGE

62. Kohl E, McCutcheon P (2015) Kitchen table reflexivity: negotiating positionality through everyday talk. Gend Place Cult 22:747-763. https://doi. org/10.1080/0966369X.2014.958063.

63. Bourdieu P, Wacquant $L J$ (1992) An invitation to reflexive sociology. University of Chicago Press, Chicago

64. Gunasekara C (2007) Pivoting the centre: reflections on undertaking qualitative interviewing in academia. Qualitative Research 7:461-475. https://doi.org/10.1177/1468794107082302

65. England KV (1994) Getting personal: reflexivity, positionality, and feminist research. Prof Geogr 46:80-89. https://doi.org/10.1111/j.0033-0124.1994. 00080.x.

66. Defila R, Di Giulio A (2018) What is it good for? Reflecting and Systematizing Accompanying Research to Research Programs. GAIA - Ecological Perspectives for. Science and Society 27:97-104. https://doi.org/10.14512/gaia.27.S1.17

67. Witzel A, Reiter H (2012) The problem-centred interview. Sage, Los Angeles a.o.

68. Schiffer E, Hauck J (2010) Net-Map: collecting social network data and facilitating network learning through participatory influence network mapping. Field Methods 22:231-249. https://doi.org/10.1177/ $1525822 \times 10374798$

69. Schneider F, Buser T (2018) Promising degrees of stakeholder interaction in research for sustainable development. Sustain Sci 13:129-142. https://doi. org/10.1007/s11625-017-0507-4

70. Mayring P (1991) Qualitative in halts analyse. In: Handbuch Qualitative Sozialforschung. Grundlagen, Konzepte, Methoden und Anwendungen. Psychologie Verlags Union, München
71. Gibbs GR (2008) Analysing qualitative data. Sage

72. Akrich M (1992) The description of technical objects. In: Bijker WE, Law J (eds) Shaping technology/building society, studies in socio technical change. MIT Press, Cambridge, MA, pp 205-224

73. Völker T (2014) "Futuring" in transdisciplinary sustainability research. University of Vienna

74. Patton MQ (1999) Enhancing the quality and credibility of qualitative analysis. Health Serv Res 34:1189

75. Di Giulio A, Defila R, Brückmann T (2016) "Das ist halt das eine ... Praxis, das andere ist Theorie"-Prinzipien transdisziplinärer Zusammenarbeit im Forschungsalltag. In: Defila R, Di Giulio A (eds) Transdisziplinär forschenzwischen Ideal und gelebter Praxis: Hotspots, Geschichten, Wirkungen. Campus Verlag

76. Kanter RM (2008) Men and women of the corporation: new edition. Basic books, New York

77. Defila R, Di Giulio A (2019) Eine Reflexion über Legitimation, Partizipation und Intervention im Kontext transdisziplinärer Forschung. In: Ukowitz M; Hübner R (eds) Interventionsforschung alsVermittlung zwischen Wissenschaft und Praxis. Einblicke in methodologische Fragen transdisziplinärer Forschung. Springer, Wiesbaden, 85-108

78. Castree N, Adams WM, Barry J, Brockington D, Büscher B, Corbera E, Demeritt D, Duffy R, Felt U, Neves K (2014) Changing the intellectual climate. Nat Clim Chang 4:763. https://dx.doi.org/10.1038/nclimate2339.

79. Tötzer T, Sedlacek S, Knoflacher M (2011) Designing the future-a reflection of a transdisciplinary case study in Austria. Futures 43:840-852. https://doi. org/10.1016/j.futures.2011.05.026

80. Stirling A (2008) "Opening up" and "closing down" power, participation, and pluralism in the social appraisal of technology. Sci Technol Hum Values 33: 262-294. https://doi.org/10.1177/0162243907311265.

\section{Publisher's Note}

Springer Nature remains neutral with regard to jurisdictional claims in published maps and institutional affiliations.

\section{Submit your manuscript to a SpringerOpen ${ }^{\circ}$ journal and benefit from:}

- Convenient online submission

- Rigorous peer review

- Open access: articles freely available online

- High visibility within the field

- Retaining the copyright to your article

Submit your next manuscript at $>$ springeropen.com 